\title{
Os Usos e Papéis dos Ambientes Virtuais de Aprendizagem e Ferramentas Tecnológicas: uma Análise dos Trabalhos do ENPEC sobre Educação a Distância
}

\begin{abstract}
Uses and Roles of Virtual Learning Environments and Technological Tools: Analyzing ENPEC's Articles on Distance Education
\end{abstract}

\author{
Rutiléa Mendes de Morais, ${ }^{(1)}$ Rodrigo da Luz, Benedito Gonçalves Eugênio
}

Palavras-chave

Educação a

Distância;

AVA;

Ensino de Ciências;

Revisão Sistemática

de Literatura.
Resumo A Educação a Distância tem se desenvolvido de modo significativo nos últimos anos nas diversas áreas do conhecimento, incluindo o campo da Educação em Ciências. Levando em consideração essa expansão e o desenvolvimento dessa modalidade, o presente trabalho tem como objetivo analisar e caracterizar a produção científica sobre ferramentas multimídias e ambientes virtuais no ENPEC quanto aos seus usos e papéis no processo de ensino e aprendizagem em Ciências. Para isso, consideramos o período de 2007 a 2019 para levantamento das pesquisas e utilizamos a Análise de Conteúdo para a análise das informações textuais. Os resultados mostram que existem poucos trabalhos que se dediquem a tratar das ferramentas tecnológicas e dos ambientes virtuais destinados ao processo de ensino e aprendizagem. Os trabalhos apontam para os usos dessas ferramentas e ambientes virtuais como dimensões científico-tecnológicas que medeiam as relações entre os participantes, com preponderância da utilização do AVA, chats e fóruns, ao passo que evidenciam os papéis que desempenham e/ou viabilizam relacionados a motivação e interação entre os participantes, a adoção de posturas científicas e a relação entre diferentes saberes. $\mathrm{O}$ que se percebe é que esses meios e possibilidades digitais apresentam potencialidades a serem exploradas no ensino de ciências, seja na variedade das ferramentas, seja no uso diferenciado que é conferido a elas, não havendo trabalhos que envolvam a diversificação desses recursos. 
Keywords Abstract Distance Education has developed significantly in recent Distance Education; years in various areas of knowledge, including that of Science

VLE; Education. Taking into account this expansion and the development Science Teaching; of this modality, the present work aims to analyze and characterize Systematic ENPEC's scientific production on multimedia tools and virtual Literature Review. environments, in relation to their uses and roles in science teaching and learning processes. For this, we considered the period from 2007 to 2019 and used Content Analysis to analyze the textual information. The results show that there are few studies dedicated to dealing with technological tools and the virtual environments where the teaching and learning processes take place. The articles point to the uses of these tools and virtual environments as scientific-technological dimensions that mediate the relationships between the participants, being VLEs, chats and forums the predominant tools used. The studies also highlight the roles and possibilities related to motivation and interaction between the participants, the adoption of scientific postures and the relationship between different knowledge that these tools offer. What is perceived is that these means and digital possibilities have the potential to be explored in science education, either because of the variety of tools available or the different uses that are given to them, although no studies have observed the diversification of these resources.

\section{Introdução}

A Educação a Distância $(\mathrm{EaD})$ tem crescido de maneira significativa no cenário brasileiro, tornando-se uma realidade dentro do contexto acadêmico e, como qualquer outra modalidade de ensino, apresenta potencialidades a serem exploradas no processo de construção do conhecimento. Trata-se de uma modalidade de educação que se utiliza das Tecnologias de Informação e Comunicação (TIC) para intermediar a relação entre alunos e professores que estão separados fisicamente seja no tempo e/ou no espaço, podendo haver ou não momentos presenciais ${ }^{1}$ (Moran, 2006). Essa configuração tornouse fundamental para a constituição da $\mathrm{EaD}$, facilitando a interação entre seus principais atores (estudantes, coordenadores, tutores, orientadores ou formadores).

No Brasil, a EaD teve início no século XIX, com a datilografia por meio de correspondência, seguida pelo rádio e, posteriormente, a televisão. Nos dias atuais é impulsionada por meio das TIC (Silva et al., 2014). Essas tecnologias são fundamentais para a transposição dos obstáculos espaço-temporais que podem servir como verdadeiras barreiras para aqueles que desejam estudar, mas que se encontram distantes de instituições de ensino ou cujos horários de trabalho não os permite acompanhar um curso presencial.

\footnotetext{
1 Apesar de ser amplamente difundida e conhecida em território nacional como EaD, o Ministério da Educação (MEC) recomenda que as instituições de ensino incorporem ao menos $20 \%$ dos cursos dessa natureza em formato semipresencial, normatização que de acordo com Rodrigo Junior \& Fernandes (2014) não reverbera em todas as instituições brasileiras de ensino.
} 
A oferta de cursos EaD é crescente nas últimas décadas, inclusive daqueles voltados à formação de professores de Ciências no Brasil (Garcia \& Gouw, 2009), sem que se saiba, entretanto, o quantitativo de pesquisas que discutem as implicações e desafios que perpassam um ensino dessa natureza e nessa área, muito menos os sentidos e práticas que estão sendo produzidos sobre essa modalidade educativa no contexto da Educação em Ciências de maneira ampla. Em todo caso, há a necessidade de compreender a EAD como possibilidade de superação paradigmática que vem desestabilizar as certezas que temos relativas à construção de saberes no ensino e aprendizagem de Ciências, como ressalta Silva et al. (2014, p. 42):

Com o crescimento exponencial da $\mathrm{EaD}$, surge a necessidade de conhecimento e indubitavelmente a necessidade de adaptação de todos em relação a esse método de ensino. Dessa forma, é de grande valia a quebra de paradigmas que a maior parte do corpo social possui quando se refere à qualidade de ensino nessa modalidade. Para profissionais e alunos da área de licenciaturas, o estudo aprofundado dessa modalidade de ensino possibilita a interação em relação a esse método, permite a quebra de antigos paradigmas e, por conseguinte, faz com que percebam a indispensabilidade de adequação, para que estejam preparados para essa forma de atuação (Silva et al., 2014, p. 42).

Diante disso, percebemos que com a implementação da EaD nas universidades brasileiras, essas instituições tiveram que se ressignificar para conseguir dar conta das especificidades formativas requeridas, uma vez que nessa modalidade o processo de ensino e aprendizagem acontece por meio da interação entre tutores, orientadores, formadores e cursistas mediado pelas tecnologias pedagógicas.

Moran (2006) aponta que apesar da rápida expansão da EaD no Brasil, essa modalidade ainda não possui um modelo de educação consolidada e investigada. Sendo assim, a maior parte das pesquisas nessa área focam em experiências próprias, residindo nesse fato uma das dificuldades que existe de visualizar as entrelinhas desse processo.

Nesse sentido, levando em conta a expansão e o desenvolvimento da EaD, torna-se importante a realização de pesquisas que possam analisar esse crescimento no âmbito da Educação em Ciências, foco do presente artigo, apontando lacunas, perspectivas e potencialidades dessa modalidade para a área, sobretudo quando se tratam das ferramentas multimídias ou tecnológicas e dos ambientes virtuais destinados ao processo de ensino e aprendizagem. Diferentemente do ensino de ciências presencial, aquele desenvolvido na $\mathrm{EaD}$ apresenta uma dependência muito maior dos elementos científico-tecnológicos presentes na sociedade da informação. Sem as tecnologias digitais, essa modalidade de ensino não teria tal amplitude e isso reforça a necessidade de estudos na área para se ter uma compreensão articulada entre os diferentes atores e as ferramentas que intermediam o processo de ensino e aprendizagem.

É preciso compreender que o ensino de ciências tem fundamentos epistemológicos e didático-pedagógicos próprios, sob os quais se assentam os processos de ensino e aprendizagem de temas sociais e/ou conceitos científicos, sendo desejável 
e imprescindível que esses fundamentos balizem a $\mathrm{EaD}$ e, nesse processo, também sejam por ela ressignificados. Entretanto, não é difícil perceber a falta de consenso entre os pesquisadores da área de Educação em Ciências quanto às formas do que, como $\mathrm{e}$ porque ensinar (Nardi \& Almeida, 2007), mesmo na modalidade presencial, o que sem dúvida também se constitui como um desafio para o ensino de ciências na modalidade à distância.

Em diferentes espaços educativos, as tecnologias digitais ainda são pouco utilizadas ou tratadas de forma inadequada à formação de sujeitos críticos, aspectos que são intensificados quando não há a diversificação e o tratamento científico dos recursos digitais utilizados, bem como a necessária preocupação com o objeto do conhecimento sobre o qual incidirá a reflexão tanto de estudantes quanto de professores (Novais, 2009). A separação espacial e/ou temporal não significa ausência no processo educativo e, nesse sentido, não podemos pensar um ensino de ciências à distância que se distancie do cotidiano e do dia a dia do estudante, razão pela qual temos que refletir sobre a formação de professores e estudantes considerando aportes das tecnologias digitais aplicadas ao ensino de ciências na direção de estruturar processos educativos comprometidos com a realidade.

A Educação em Ciências no Brasil pode ser entendida como um campo relativamente autônomo, formado por pesquisadores que historicamente vêm produzindo e disseminando pesquisas das mais diversas linhas teórico-metodológicas em cursos de graduação e pós-graduação, bem como em livros, periódicos e eventos. Um desses eventos é o Encontro Nacional de Pesquisa em Educação em Ciências (ENPEC), que desde o ano de 1997 vem contribuindo com a consolidação da pesquisa em ensino de ciências no Brasil, reunindo o que há de mais recente em termos de produção científica.

Considerando a representatividade do ENPEC e a importância que a EaD tem no contexto da Educação em Ciências, neste artigo buscamos responder a seguinte questão: em que medida os trabalhos apresentados nos anais do ENPEC têm abordado acerca das ferramentas multimídias e os ambientes virtuais no ensino de ciências? Entendemos que o ENPEC não é um evento específico sobre $\mathrm{EaD}$, entretanto partimos da hipótese de que nesse evento haveria um interesse por parte dos pesquisadores em construir conhecimentos relativos as ferramentas de multimídia e os ambientes virtuais de aprendizagem para o ensino de ciências, uma vez que esses saberes são colocados como demandas em um mundo cada vez mais marcado pela dimensão científico-tecnológica, pela rapidez no fluxo de informações e pelo encurtamento das distâncias promovido pelo avanço da internet e das telecomunicações (Delizoicov et al., 2018).

Dessa forma, o objetivo deste trabalho é analisar e caracterizar a produção científica sobre ferramentas multimídias e ambientes virtuais no ENPEC quanto aos seus usos e papéis no processo de ensino e aprendizagem em Ciências. Ao passo que investigamos esse objeto de estudo, buscaremos evidenciar as tecnologias digitais mais utilizadas pelos pesquisadores, elencando suas potencialidades, limites e perspectivas dentro desse contexto de produção de conhecimentos e práticas. 


\section{Partindo de uma Perspectiva Histórica}

Foram muitas as modificações no que diz respeito às inovações e movimentos tecnológicos ao longo dos anos para que a EaD adquirisse a atual configuração. Para compreender seu avanço nos dias atuais e de que maneira foram delineadas as relações de ensino e aprendizagem nessa modalidade, é preciso recorrer aos aspectos históricos de sua constituição.

Sobre a $\mathrm{EaD}$, Silva et al. (2015) dizem que a modalidade já não é novidade no mundo educacional, uma vez que os primeiros registros de sua utilização foram identificados em " 1728 , por meio de um curso por correspondência na cidade de Boston, nos Estados Unidos” (p. 203).

Algumas pesquisas mostram que no Brasil a EaD teve início no século XIX, quando passou a ser disponibilizado o ensino de datilografia por meio de correspondência, seguido pelo rádio e, posteriormente, a televisão (Silva et al., 2014). Por volta de 1904, as escolas internacionais, que eram instituições privadas, disponibilizavam cursos pagos, por correspondência. Trinta anos depois, em 1934, surgiram o Instituto Monitor e o Instituto Universal Brasileiro, em São Paulo, que ajudaram a disseminar essa modalidade educativa (Costa \& Faria, 2008).

Martins (2011) aponta que a evolução dos meios de comunicação teve o seu estopim com a internet nos anos de 1990 e 2000, propiciando um ensino mais diversificado, dinâmico e atrativo para a população que buscava flexibilidade de tempo e de espaço. A existência de uma rede de conexão, que pudesse oferecer uma comunicação rápida (online) entre alunos e professores, acabou por aumentar as possibilidades da EaD.

Nesse sentido, com a ampliação das universidades e faculdades que oferecem a EaD no Brasil aumentou também a oferta de cursos e matrículas para essa modalidade. Isso criou demandas e desafios sem precedentes, principalmente quando se refere à qualidade e delineamento da EaD.

De acordo com Sanchez (2005), o número de instituições autorizadas pelo MEC para prover a modalidade EaD cresceu 36\% entre 2004 e 2006. Os cursos de graduação $\mathrm{EaD}$ tiveram um aumento de $74 \%$ e o número de vagas $274 \%$ no período entre 2004 e 2005. Em 2005, cerca de 504 milhões de alunos estudavam EaD no Brasil. Nesse sentido:

Esta ampliação das unidades escolares e das matrículas ocorreu de maneira acelerada e o aumento da demanda de professores foi uma consequência inevitável. Devido às facilidades que a modalidade tem oferecido nos dias atuais foram ampliados os cursos e matrículas neste sentido de maneira acessível inclusive financeiramente (Carneiro \& Silva, 2014, p. 9).

Em referência à organização da EaD no ensino de ciências e os seus desdobramentos no cenário da UAB, Lima (2014) reflete sobre o arcabouço histórico que propiciou o fomento desses cursos. Haja vista que com a formação docente sendo cada vez menos prestigiada, tanto do ponto de vista salarial quanto social, foi plausível incrementar políticas públicas que visassem reduzir a defasagem de professores com formação 
específica que atuavam no Ensino Médio. Dentre as prioridades, os cursos de Biologia, Química, Física e Matemática apresentavam um grande déficit, principalmente quando a estimativa evidenciava a necessidade docente relacionada aos formados lecionando no Ensino Médio e o número de licenciados formados por ano. Considerando esse cenário, a área de ensino de ciências passou a ter um maior enfoque no contexto da EaD e por isso esses cursos obtiveram ascensão em número de vagas a partir de 2005, como tentativa de reverter a falta desses profissionais no mercado de trabalho.

Destacamos que a Universidade Aberta do Brasil (UAB) foi criada em 2006 pelo governo Lula e nesse período é notório o crescimento da $\mathrm{EaD}$ no Brasil. Todavia, é importante destacar que alguns fatores recentes têm propiciado uma mudança neste cenário tanto no setor público quanto no privado. No setor público, a UAB sofreu um sucateamento de repasses e algumas universidades anunciaram a suspensão de processos seletivos em andamento ${ }^{2}$. Não obstante, Segenreich (2009) critica que, apesar dos desdobramentos da $\mathrm{EaD}$, atualmente não se tem um panorama desta modalidade de ensino no que se refere a dados quantitativos exatos. Nos diferentes espaços sociais, a problemática se intensifica em decorrência da emergência da pandemia do SARSCoV-2 que emergiu no final do ano de 2019, aprofundando as desigualdades sociais e aumentando, portanto, o fosso existente entre ricos e pobres. Essa situação de emergência planetária tem levado ao aumento do desemprego, à fragilização emocional e psicológica, bem como prejuízos à saúde que no limite podem estar contribuindo para que ocorram desistências dos cursos à distância. Por outro lado, a pandemia tem colocado a necessidade de estudos não presenciais como forma de prevenção da população contra a ameaça de contaminação viral, o que também pode repercutir na valorização dessa modalidade educativa. Acreditamos que esses fatores ainda recentes afetarão significativamente o cenário do ensino de ciências na modalidade EaD nos próximos anos.

Diante desse cenário, trazemos algumas reflexões sobre elementos presentes nessa modalidade de ensino que dizem respeito à inserção de tecnologias e à forma como elas promovem o contato e a interação entre os diferentes atores da $\mathrm{EaD}$, culminando em um processo de ensino e aprendizagem diferenciado e que guarda características próprias. Para Abreu-Tardelli (2006), essas tecnologias na forma de ferramentas multimídias e ambientes de aprendizagem são o núcleo da $\mathrm{EaD}$, como será discutido adiante.

$\mathrm{Na} \mathrm{EaD}$ os diferentes atores que a compõem como coordenadores, estudantes, tutores, orientadores ou formadores têm um papel importante para o desenvolvimento desta modalidade. $\mathrm{O}$ coordenador de polo participa ativamente no desenvolvimento do curso, desde a elaboração do vestibular até a seleção dos tutores. O coordenador

2 A título de exemplificação, citamos a suspensão em 2019 do processo seletivo para cursos na modalidade $\mathrm{EaD}$ da Universidade Estadual de Santa Cruz. Maiores informações a esse respeito podem ser acessadas por meio dos links: https://www.otabuleiro.com.br/blog/apos-corte-do-mec-uesc-suspende-cursos-ead; http:// polouabvitoriadaconquista.blogspot.com/2019/09/nota-de-esclarecimento-ead-uab-uesc.html. Citamos ainda a falta de recursos da Universidade Federal de Minas Gerais para manter seus cursos EaD em funcionamento diante dos constantes cortes de verbas destinados a essa modalidade educativa. Informações a esse respeito podem ser acessadas por meio do link: https://www.ufmg.br/ead/index.php/2019/04/04/5159/. 
do curso é responsável por gerenciar a implementação e o andamento das atividades de acordo com o plano pedagógico construído, atuando na confecção dos materiais, na organização e regulamentação do curso. Outro partícipe é o professor conteudista, que é designado para produzir o material didático, ministrar aulas (modo síncrono e assíncrono), acompanhar e auxiliar os tutores. Enquanto os professores formadores intermedeiam os processos de ensino e aprendizagem, avaliam e esclarecem as dúvidas dos discentes de modo presencial no polo, os tutores, em geral, realizam esse suporte de modo prioritariamente online, sendo que a instituição de nível superior pode contar também em alguns casos com tutores presenciais (Nobre et al., 2008). Os cursistas da EaD, por sua vez, têm de fato uma grande responsabilidade no seu processo de aprendizagem. Apesar de serem mais autônomos em relação à organização da sua disponibilidade de lugar e horário para estudar, esses devem realizar as tarefas solicitadas, organizar o tempo de estudo, estabelecer comunicação com os demais atores, realizar atividades, apresentar trabalhos em grupos, dentre outras tarefas. Silva (2004) retrata que é imprescindível que esses estejam motivados, tendo em vista a sua função ativa ao longo do processo (Silva, 2004). A participação e o engajamento mediados pelos processos de comunicação estabelecidos entre esses atores são elementos fundamentais para desenvolver um curso $\mathrm{EaD}$ de qualidade e que forneça elementos para a formação autônoma dos discentes.

\section{Ambiente Virtual de Aprendizagem e Ferramentas Tecnológicas na EaD}

As TIC são um conjunto de recursos tecnológicos que, se estiverem integrados entre si, podem propiciar a automação e/ou a comunicação, atuando, portanto, como ferramentas capazes de reunir, distribuir e compartilhar informações no âmbito da $\mathrm{EaD}$ (Mendes, 2010).

É evidente o quanto a tecnologia foi uma importante aliada para essa modalidade, servindo como base de suas principais dimensões pedagógicas. De acordo com Lengler (2014), a partir de 1990 com o avanço da internet, da rede de satélites, de programas de suporte informático e materiais didáticos digitalizados, a qualidade da $\mathrm{EaD}$ e, sobretudo, sua abrangência aumentaram, com destaque para a internet que possibilitou a integração de todo o sistema pedagógico da EaD.

$\mathrm{Na} \mathrm{EaD}$, as atividades são realizadas tendo como principal cenário os Ambientes Virtuais de Aprendizagem (AVA) que consistem em programas que permitem o armazenamento, administração e disponibilização de conteúdos no formato web, além de criar condições para que ocorra a comunicação entre os diferentes participantes (Ministério da Educação, 2007). Por meio dessas características, o AVA pode ser acessado em qualquer lugar, de forma autônoma, desde que se tenha internet com velocidade capaz de suportá-lo, já que não é necessária a manipulação, ou seja, os alunos não precisam desenvolver as atividades ao mesmo tempo. Dessa forma, contanto que respeitem os prazos de postagem, os alunos podem estudar de acordo com um ritmo próprio, o que representa uma vantagem para aqueles que trabalham e/ou não tem disponibilidade de tempo para cursar uma graduação presencial (Abreu-Tardelli, 2006; Tenório et al., 2015). 
Os AVA contribuem significativamente para a organização pedagógica dos cursos, sobretudo na transposição da barreira de tempo e espaço, possuindo um caráter formativo que viabiliza processos didático-pedagógicos. Levando em consideração que os AVA simulam o espaço da sala de aula (Oliveira et al., 2015), alguns de seus benefícios na comunicação por meio da $\mathrm{EaD}$ estão relacionados à possibilidade de trocas contínuas de informações de forma flexível, favorecendo a interação entre os participantes, a autonomia do aluno e a construção coletiva do conhecimento (Hamawaki \& Pelegrini, 2009; Morgado, 2001; Ribeiro et al., 2007).

Minus e Sorte (2011), ao retratarem sobre a importância e a necessidade de estudar esses ambientes de aprendizagem, acrescentam que:

Devido à grande gama de AVA existentes no mercado, cada vez se exige mais da qualidade destas ferramentas e dos recursos por elas disponibilizados. As plataformas devem disponibilizar grande interação, assim simulando uma sala de aula online, por este motivo os recursos contidos nos AVA devem ser avaliados de maneira minuciosa visando abranger pedagogicamente os alunos e suas características pessoais de aprendizagem (Minus \& Sorte, 2011, p. 3).

Para atuar no AVA, professores, alunos e tutores fazem uso de diferentes ferramentas tecnológicas, indispensáveis para a $\mathrm{EaD}$, pois são responsáveis pela comunicação no processo de ensino e de aprendizagem entre atores que se encontram separados no tempo e no espaço. A partir do momento em que educadores e educandos estão em sintonia com as ferramentas tecnológicas, com suas rotinas de acesso, bem como com as complementações das práticas presenciais, as possibilidades de sucesso para o processo de ensino e aprendizagem na EaD são amplificadas (Teixeira et al., 2015).

Sobre a utilização dessas ferramentas de multimídia Paula Filho (2000) diz que elas buscam propiciar a interação entre dois ou mais seres humanos ou entre seres humanos e objetos que estão envolvidos em uma ação. As interações entre esses agentes podem ocorrer por meio de diferentes representações da informação como exposições sonoras, visuais e audiovisuais. Essas configurações também podem atuar em conjunto, todas mediadas pela ciência e tecnologia.

De acordo com sua funcionalidade, podemos classificar as ferramentas de multimídia mais utilizadas na EaD conforme estão dispostas na Figura 1: 
Figura 1. Distribuição e finalidades das principais ferramentas da EaD

\begin{tabular}{|l|l|}
\hline \multicolumn{1}{|c|}{ Ferramentas } & \multicolumn{1}{c|}{ Funcionalidades } \\
\hline Fóruns & $\begin{array}{l}\text { Constituídos de temas definidos pelos docentes debatidos em grupo. É } \\
\text { um importante espaço para troca de experiências e informações. Pode ser } \\
\text { realizado de maneira assíncrona, isto é, sem a necessidade de ocorrer em } \\
\text { tempo real. }\end{array}$ \\
\hline Chat & $\begin{array}{l}\text { Semelhante ao fórum, mas proporciona integração entre os participantes de } \\
\text { maneira síncrona, uma vez que precisa ocorrer em tempo real. }\end{array}$ \\
\hline Correio Eletrônico & $\begin{array}{l}\text { Recurso utilizado para envio de comunicados e troca de informações, } \\
\text { normalmente, relacionadas ao curso. }\end{array}$ \\
\hline $\begin{array}{l}\text { Ambiente Virtual de } \\
\text { Aprendizagem }\end{array}$ & $\begin{array}{l}\text { Ambiente que apresenta variadas ferramentas no intuito de propiciar } \\
\text { uma gama de interações entre os participantes. Além de alocar essas } \\
\text { ferramentas, se constitui em um espaço de disponibilização de materiais de } \\
\text { apoio e complementares que subsidiam o tema da disciplina. Por agregar } \\
\text { as ferramentas tecnológicas e abarcar a interação entre os envolvidos no } \\
\text { processo, torna-se crucial no processo educativo a distância, sendo utilizado } \\
\text { como comparativo ao espaço da sala de aula. }\end{array}$ \\
\hline Mural de avisos & Ambiente apropriado para comunicados e divulgações de avisos oficiais. \\
\hline Enquete & $\begin{array}{l}\text { Espaço para pesquisa de opinião. Serve como instrumento para obter } \\
\text { opiniões diversas. }\end{array}$ \\
\hline Teleconferência & $\begin{array}{l}\text { Ferramenta que utiliza uma tecnologia de telecomunicação e que permite a } \\
\text { dois ou mais indivíduos, geograficamente separados, conversarem entre si. }\end{array}$ \\
\hline
\end{tabular}

Fonte: Adaptado de Lengler (2014).

Para Maia (2003), essa mediação por meio das tecnologias computacionais e ferramentas de interação representam uma mudança na interface educacional, pois transforma o ensino em um compartilhamento de aprendizagem, excluindo do processo de aprendizagem as características habituais inerentes à modalidade presencial do ensino, que, muitas vezes, se encontra pautada na autoridade do professor. Essa perspectiva que entende as tecnologias digitais como possibilidade de superação de práticas tradicionais é ressaltada por Lopes et al., (2014) em atividades realizadas no ensino de ciências com alunos da Educação Básica, utilizando ambientes virtuais e ferramentas tecnológicas. Os autores evidenciam que há a dedicação de um tempo maior para os estudos por parte dos discentes que participam mais ativamente dos encontros, tendo em vista que o ambiente virtual propicia a troca de experiências e a circulação de informações entre os participantes, fato que pode contribuir para a superação do formato unidirecional da aprendizagem no ensino de ciências.

Em suas pesquisas sobre as tecnologias e as ferramentas na EaD com a utilização do chat, correio eletrônico e fórum, autores concluem que essas diferentes ferramentas são de extrema importância para a formação crítica dos sujeitos em um mundo marcado por interações virtuais, sendo potencializadas se utilizadas em conjunto (Hamawak \& Pelegrini, 2009; Maia, 2003; Oliveira et al., 2015). Para além disso, Martinho e 
Pombo (2009) ressaltam que essas ferramentas no ensino de ciências podem propiciar uma reestruturação dos processos de ensino, possibilitando o desenvolvimento das capacidades de interação e reflexão.

\section{Metodologia}

Esta pesquisa se caracteriza como qualitativa, visto que tem como características a descrição, a interpretação dos fenômenos e a atribuição de significados, sem se preocupar com a operacionalização de variáveis matemáticas ou com o tratamento estatístico dos dados (Marconi \& Lakatos, 2003). Ainda pode ser caracterizada como do tipo bibliográfica, uma vez que é desenvolvida a partir de materiais já produzidos e tornados públicos cujas informações são trazidas para a atualidade da discussão dos fatos (Gil, 2010), caracterizando-se como revisão sistemática da literatura. A revisão sistemática contribui para identificar como as informações levantadas sobre uma temática em determinada base de dados vem sendo abordada, auxiliando a verificar lacunas e a direcionar novos estudos sobre o tema.

Tomamos com objeto de estudo as atas de um dos principais eventos da área de Educação em Ciências, o ENPEC, nas quais levantamos a produção científica desenvolvida nos últimos doze anos (2007-2019) sobre a EaD. Apesar de haver outros eventos no campo do ensino de ciências, tais como: SNEF - Simpósio Nacional de Ensino de Física, EPEF - Encontro de Ensino de Pesquisa em Física, ENEBIO - Encontro Nacional de Ensino de Biologia e ENEQ - Encontro Nacional do Ensino de Química, escolhemos o ENPEC por ser um evento mais abrangente que traz a integralidade do ensino de ciências no que diz respeito a concentração de áreas (Biologia, Química e Física) e a trabalhos publicados sobre diferentes temáticas. Vale ressaltar que esse é um dos maiores eventos de Educação em Ciências e, como tal, partimos da hipótese de que nele estão presentes as pesquisas mais recentes e relevantes que se situam na articulação entre a EaD e o ensino de ciências de maneira ampla, além de seus desdobramentos no que tange principalmente a formação de professores de ciências, processos de ensino e aprendizagem, modalidades de ensino, recursos e ferramentas didático-pedagógicas, tecnologias para o ensino de ciências etc.

O recorte temporal 2007-2019 foi escolhido como possibilidade de levantar tanto pesquisas mais antigas quanto mais recentes que investiguem a EaD atrelada ao ensino de ciências. Além disso, foi nesse período que ocorreu a expansão dessa modalidade nas universidades públicas brasileiras, a partir da aprovação dos cursos superiores regidos pela Universidade Aberta do Brasil (Moran, 2006).

Para realizar a coleta de dados utilizamos os mecanismos de busca presentes nos sites do evento. Procuramos localizar nos títulos, resumos e palavras-chave os seguintes termos: Ensino à Distância, Educação à Distância ou a sigla EaD.

Partimos dessas palavras-chave de maior abrangência porque representam nosso interesse de pesquisa, ou seja, queríamos a partir delas investigar as ferramentas multimídias e ambientes virtuais de aprendizagem que estivessem sendo usadas 
exclusivamente para promover processos de ensino e aprendizagem e/ou formação de professores em cursos realizados na EaD no contexto da Educação em Ciências.

Os trabalhos selecionados a partir dessa primeira busca foram lidos na íntegra e analisados com base na Análise de Conteúdo (AC). Para Moraes (1999), a AC possui cinco etapas básicas:

a) Preparação das informações, na qual ocorre a identificação das diferentes amostras das informações mediante a leitura. Esse olhar deve direcionar a leitura em consonância com o objetivo da pesquisa. Nesse processo, ocorre também a codificação que permite identificar cada elemento da amostra a ser analisada.

b) Unitarização, na qual acontece a releitura dos textos com o objetivo de desintegrá- los de acordo com o interesse da investigação. Por meio dessa fragmentação são encontradas as unidades de análise que concentram o entendimento do texto como um todo.

c) Categorização, na qual as unidades de análise semelhantes são reunidas em categorias. As categorias podem ser definidas a priori, que se referem às construções que o pesquisador organiza antes da análise dos dados, ou seja, na qual os dados são examinados com base em teorias escolhidas previamente; e/ou emergentes, quando o pesquisador se utiliza de construções teóricas organizadas a partir do corpus que é composto pelos textos obtidos através dos trabalhos. Em nossa pesquisa, a partir da análise dos trabalhos, emergiram três categorias: (a) Ambientes Virtuais de aprendizagem e ferramentas tecnológicas; (b) percepções e trabalhos desenvolvidos na Educação à Distância; e (c) pesquisas de levantamento. O foco do presente trabalho foi analisar a categoria "a". Para isso, essa categoria foi desdobrada em subcategorias. A primeira sobre o ambiente virtual de aprendizagem e a segunda sobre as Ferramentas Multimídias e Ferramentas tecnológicas. Em torno dessas subcategorias organizamos o trabalho.

d) Descrição, constitui a etapa de expressão dos sentidos obtidos com as categorias analisadas. Esse momento de expressão da mensagem é fundamental para ancorar a etapa seguinte.

e) Interpretação, representa a culminância do processo de análise, já que o objetivo da $\mathrm{AC}$ não se restringe somente à descrição. Nesse sentido, representa uma espécie de diálogo entre os dados, a interpretação das pesquisadoras e o referencial teórico. Sua finalidade é produzir uma compreensão profunda a respeito dos objetos de análise.

Como permite a metodologia, inserimos na análise trechos dos trabalhos pesquisados (identificados de T1 a T6). Nesses, destacamos algumas expressões em negrito, que não estavam presentes no material original e que se referem a elementos e unidades de sentido que queremos aprofundar em nossa análise. Ainda nessa etapa, conseguimos evidenciar por meio das interpretações destes trabalhos os usos e papéis das ferramentas tecnológicas e dos ambientes virtuais de aprendizagem. 


\section{Resultados e Discussões}

Ao longo das sete edições do ENPEC, correspondentes ao período de 12 anos, foram publicados um total de 7543 trabalhos pertencentes às distintas linhas de pesquisa, modalidades e níveis de educação no âmbito da Educação em Ciências. Desse total, apenas 30 trabalhos $(0,39 \%)$ tratam sobre a EaD. Em processos de leituras sistemáticas desse conjunto de trabalhos, organizamos os artigos em três categorias principais, em consonância com os objetivos propostos: (a) Ambientes Virtuais de aprendizagem e ferramentas tecnológicas; (b) percepções e trabalhos desenvolvidos na Educação a Distância; e (c) pesquisas de levantamento.

O foco do presente trabalho foi analisar os trabalhos elencados na categoria "a" que retrata o uso de ferramentas multimídias e de ambientes virtuais de aprendizagem nos trabalhos do ENPEC. Diante disso, essa categoria foi desdobrada em subcategorias. A primeira sobre o ambiente virtual de aprendizagem e a segunda sobre as Ferramentas Multimídias e Ferramentas tecnológicas. Em torno dessas subcategorias organizamos e aprofundamos a pesquisa.

Apontamos que o enfoque na análise dessa categoria tem como pressuposto os limites de um artigo e também a escassez de trabalhos no ensino de ciências que visem a compreender os desdobramentos do AVA e das Ferramentas Tecnológicas em diferentes níveis educativos. Para entender a relevância de estudar de maneira mais sistemática as tecnologias digitais no ensino de ciências é necessário compreender as entrelinhas que constituem esse processo, visando contribuir para a melhoria dos ambientes e ferramentas de aprendizagem, já que paulatinamente esses vêm sendo utilizados em práticas e atividades para o ensino de ciências (Martinho \& Pombo, 2009; Ferrari et al., 2009; Sales \& Melo, 2017). Levando em consideração que o desenvolvimento de uma $\mathrm{EaD}$ de qualidade perpassa pela compreensão dessas ferramentas, dos 30 trabalhos sobre $\mathrm{EaD}$ selecionamos seis que tratam especificamente desses recursos de ensino e aprendizagem, codificando-os de T1 a T6 (Figura 2). 
Figura 2. Uso de ferramentas multimídias e de ambientes virtuais de aprendizagem em pesquisas veiculadas no ENPEC no período de 2007 a 2019

\begin{tabular}{|c|c|c|c|c|}
\hline EVENTO & ANO & TÍTULO DA PESQUISA & AUTORES & CÓDIGO \\
\hline VIII ENPEC & 2011 & $\begin{array}{l}\text { Papel do Fórum na Educação } \\
\text { a Distância: estudo de caso } \\
\text { enfocando uma discussão } \\
\text { sobre ambiente marinho na } \\
\text { rede de São Paulo de Formação } \\
\text { docente }\end{array}$ & $\begin{array}{l}\text { Percia Barbosa Naomi } \\
\text { Towata Thierry Lima } \\
\text { Marina Macedo } \\
\text { Luís Carlos de Saito } \\
\text { Wellingtom Braz } \\
\text { Carvalho Delitti } \\
\text { Suzzana Ursi }\end{array}$ & $\mathrm{T} 1$ \\
\hline & & $\begin{array}{l}\text { A comunicação pedagógica em } \\
\text { um curso à distância }\end{array}$ & Anne Scarinci & $\mathrm{T} 2$ \\
\hline IV ENPEC & 2013 & $\begin{array}{l}\text { Construção de indicadores na } \\
\text { dimensão rendimento para } \\
\text { cursos de formação continuada } \\
\text { de professores em ambientes } \\
\text { virtuais de aprendizagem }\end{array}$ & $\begin{array}{l}\text { Walter de Oliveira Paulo } \\
\text { Marcelo Giordan }\end{array}$ & $\mathrm{T} 3$ \\
\hline \multirow[b]{2}{*}{$X$ ENPEC } & \multirow[b]{2}{*}{2015} & $\begin{array}{l}\text { A evolução do perfil conceitual } \\
\text { em um chat online de um curso } \\
\text { a distância de astronomia }\end{array}$ & $\begin{array}{l}\text { Jorge Deveikis Junior } \\
\text { Anne Scarinci }\end{array}$ & $\mathrm{T} 4$ \\
\hline & & $\begin{array}{l}\text { Análise da atividade assíncro } \\
\text { nas: fóruns de discussões em } \\
\text { um curso de Licenciatura em } \\
\text { Ciências Semipresencial }\end{array}$ & $\begin{array}{l}\text { Luciana F. Maganha } \\
\text { Wéliton de Souza Lopes } \\
\text { Fabiana Maris } \\
\text { Versurti-Stoque } \\
\text { Nancy Prette }\end{array}$ & T5 \\
\hline XI ENPEC & 2017 & $\begin{array}{l}\text { Ambientes virtuais como } \\
\text { configuração de aprendizagem: } \\
\text { análise de episódios interativo- } \\
\text { discursivos em um curso à } \\
\text { distância }\end{array}$ & $\begin{array}{l}\text { Luciana F. Maganha } \\
\text { Sérgio Silva Filgueira } \\
\text { Ronan S. dos Santos }\end{array}$ & T6 \\
\hline
\end{tabular}

Fonte: autoria própria.

Organizamos nosso texto para apresentar primeiramente os resultados concernentes à utilização do AVA, tendo em vista que este oferece suporte para as demais ferramentas digitais. A partir dele, discutimos os recursos que são mais utilizados, bem como os usos e papéis atribuídos a cada um deles. 


\section{O Ambiente Virtual de Aprendizagem}

O AVA é um ambiente virtual que faz alusão ao espaço da sala de aula, sendo por meio desse ambiente que ocorrem os processos interativos e a comunicação pedagógica nos mais diferentes cursos. Por esse motivo, configura-se como artefato para a EaD, sendo de fundamental importância estudos que caracterizem a sua presença, utilização e finalidade nas práticas educativas no ensino de ciências.

Nesse contexto, dentre os seis trabalhos selecionados nessa pesquisa, apenas dois relatam investigações realizadas em um curso de formação continuada para professores (T3) e um curso técnico EaD (T6), ambos desenvolvidos dentro de um AVA. Sobre essa plataforma, os trabalhos discutem que:

[...] a interatividade proporcionada pelos ambientes virtuais de aprendizagem, especialmenteem ferramentascomoosfóruns, facilita a aquisição de competências e habilidades, assim como a construção coletiva de conhecimentos, o que favorece o desenvolvimento do pensamento crítico e as possibilidades de resolução de problemas. [...] O ambiente virtual de aprendizagem MOODLE traz em seu bojo uma gama de ferramentas virtuais que registram toda a comunicação (dentre outras atividades) entre tutores, cursistas, equipe de coordenação (T3).

Percebemos que existem vários níveis e modalidades de interação em um ambiente virtual de aprendizagem [..] a investigação das interações em ambientes virtuais nos permite uma compreensão mais ampla das relações com o Saber, nos níveis epistêmico, pessoal e social (T6).

Percebe-se nos excertos que os trabalhos discutem o AVA apontando para suas potencialidades de utilização e evidenciando seu papel no processo de ensino e aprendizagem em Ciências, que correspondem a viabilização da interação, a promoção da motivação e o desenvolvimento de competências e habilidades entre os participantes, elementos necessários a efetivação do processo de comunicação. Para T3 a utilização do AVA também permite a construção de saberes de maneira colaborativa, além do desenvolvimento da criticidade que pode ajudar os alunos a desenvolverem destrezas úteis à resolução de problemas. Já T6 aposta na potencialidade que tem o AVA de contribuir para fortificar a relação entre diferentes saberes sejam eles ligados a prática científica, ao cotidiano ou a questões pessoais dos alunos. Essas potencialidades do AVA destacadas por T6 só se efetivam quando a plataforma é utilizada a partir de uma noção de educação eminentemente crítica que toma o diálogo como elemento fundante do processo de comunicação, tornando-se um espaço plural de reconhecimento, problematização e valorização das trajetórias de vida, perspectivas, valores e percepções que tem os sujeitos participantes dos momentos formativos.

Ao elencarmos os trabalhos acima e baseados em Ribeiro et al. (2007), podemos evidenciar que o AVA é um dos principais espaços onde ocorre a interação em cursos de $\mathrm{EaD}$, uma vez que possibilita a interatividade a partir da construção coletiva de 
conhecimentos. Ele simula virtualmente o ambiente da sala de aula, com uma gama de ferramentas que possibilitam a comunicação entre professores, coordenadores, cursistas e tutores.

Sobre as especificidades do AVA, Morgado (2001) acrescenta que o rompimento do tempo e espaço possibilitado pelo uso das tecnologias, não advém somente com a mudança tecnológica, mas depende também de uma alteração nas concepções sobre o que se aprende e o que se ensina, sendo que as mudanças na forma de interação entre os envolvidos nesse processo, principalmente discentes e docentes, podem refletir positivamente no processo de ensino e aprendizagem.

Ribeiro et al. (2007) apontam que a construção do ensino e o desenvolvimento do pensamento são possíveis por conta das propriedades do AVA ao apresentar os materiais de estudo de modo criativo e integrado, tornando-se atrativo, motivador e estimulante, ou seja, propiciando uma compreensão mais ampla das relações com o saber como aponta T6.

Em suma, no que se refere às pesquisas sobre o AVA, percebe-se que os dois trabalhos tiveram como objetivo analisar as potencialidades desse espaço virtual como simulador da sala de aula e base para as interações entre os diferentes atores de um curso $\mathrm{EaD}$. Por conseguinte, os trabalhos apontam que as características do AVA contribuem de forma positiva para o desenvolvimento dos processos de ensino e aprendizagem e que o ambiente possibilita um cenário que permite que os alunos desenvolvam autonomia e, consequentemente, a aprendizagem de conhecimentos científicos.

Nessa perspectiva, o ensino de ciências em ambientes virtuais requer novas maneiras de pensar e de atuar que repercutem significativamente na relação entre estudantes e professores. Há que se refletir sobre o processo de comunicação, garantindo que o receptor não apenas receba a mensagem de alguém que a emite, mas que a preencha de significados, que seja ativo no processo de construção do conhecimento e que exercite seu pensamento crítico em diálogo com os outros. Esses são alguns motivos pelos quais se reivindica a superação do ensino de ciências tradicional na direção de movimentos teórico-práticos afinados com a abertura necessária para trabalhar com as novas tecnologias da educação numa perspectiva interdisciplinar e complexa que envolve mudanças sensíveis nas características das formas de ensino e aprendizagem, na interação professor-aluno e no desenvolvimento de competências (Mayer et al., 2001).

É preciso que o professor de ciências participe de processos formativos críticos que possibilitem uma reflexão sobre o que significa ensinar e aprender na $\mathrm{EaD}$, a fim de evitar a transposição de práticas tradicionais desenvolvidas no ensino presencial, que ocorrem quando apenas se modifica a modalidade de ensino, mas a sua estrutura rígida e antidemocrática permanece inalterada.

A maior inserção no mundo digital a partir de práticas científico-tecnológicas afinadas com as demandas contemporâneas, deve ser levada em conta quando se pensa a formação do professor de ciências, considerando que essa formação, muitas vezes, não 
incorpora os elementos e pressupostos da $\mathrm{EaD}$, fazendo-se necessário refletir sobre os currículos estabelecidos, as plataformas e ferramentas digitais utilizadas e as finalidades dos processos educativos desenvolvidos.

Daí processos pedagógicos aplicados às Ciências Naturais em EaD devem primar por metodologias que levem em conta a realidade na qual o discente está inserido, façam uso proveitoso das ferramentas tecnológicas atualmente disponíveis e estejam ainda atentas às peculiaridades dessa modalidade educativa, propiciando assim inclusão social, aprendizagem significativa e construção coletiva e emancipatória do olhar científico (Novais, 2009, p. 12).

É importante ressaltar, no entanto, que para que o AVA desempenhe todas essas funções são necessárias as ferramentas tecnológicas responsáveis por propiciar as ações de interação e estratégias de comunicação que podem ocorrer por meio de exposições audiovisuais, visuais, sonoras e até abarcando múltiplas funções (Paula Filho, 2000). Além desses mecanismos das ferramentas, esse ambiente proporciona a interface com a dimensão humana sem a qual todo o aparato técnico-científico perderia sua natureza formativa e interpessoal. Nesse sentido, no âmbito das suas atribuições, coordenadores, formadores e tutores devem estar capacitados e confluentes na organização do trabalho docente para a construção da aprendizagem e o desenvolvimento integral dos discentes no contexto do ensino de ciências.

\section{As ferramentas multimídias ou tecnológicas}

Nas práticas educativas que ocorrem no contexto da $\mathrm{EaD}$, os recursos tecnológicos integrados entre si por meio de software e telecomunicações proporcionam a automação e comunicação, tendo participação inclusive dentro da pesquisa científica e no processo de ensino e aprendizagem. Devido a essas características essas ferramentas permitiram um constante aperfeiçoamento da $\mathrm{EaD}$, contribuindo com uma diversidade de mecanismos tecnológicos que são fundamentais para o ensino (Oliveira et al., 2015).

Paula Filho (2000) define as ferramentas multimídia como métodos de comunicação que ocorrem mediados pela tecnologia e que propiciam o diálogo entre alunos, professores e tutores. Sobre essas ferramentas digitais, considerando o recorte desta pesquisa, encontramos quatro trabalhos (T1, T2, T4 e T5) da área de Educação em Ciências que refletem pesquisas que tinham como função compreender e/ou investigar interações, potencialidades e desafios encontrados na utilização desses recursos multimídias. Tratando acerca dessas ferramentas, destacamos um excerto de T2:

[...] Os recursos tradicionalmente vistos como dialógicos são os fóruns de discussão, as wikis (construção de textos coletivos), as salas de bate-papo por escrito(chats), poráudioouvideoconferências. Essessão recursos prioritariamente do tipo muitos-para-muitos e são conduzidos por professores-tutores. Estes professores monitoram se a comunicação que ocorre entre os participantes está proporcionando o aprendizado almejado, ou seja, se a comunicação está sendo de fato uma comunicação pedagógica (T2). 
Percebe-se que para T2 a apresentação dessas ferramentas é atribuída como a comunicação pedagógica do curso, ou seja, elas constituem a mediação e viabilizam a aprendizagem. Ainda para a autora há a necessidade de combinação de diferentes ferramentas para que o processo de ensino e aprendizagem faça mais sentido para os estudantes. Nessa perspectiva, Hamawaki e Pelegrini (2009) afirmam que os tutores e professores descobrem cada dia mais que a verdadeira educação deve exigir a participação ativa do aluno, que deve contribuir para o desenvolvimento processual de sua própria aprendizagem, o que possibilita a construção de um conhecimento mais significativo como assinala T2.

Bacich e Moran (2018) retratam que as ferramentas tecnológicas favorecem o emprego de novos modos de expressar pensamentos, sentimentos e crenças mediante uma diversidade de contextos de comunicação. Nessa perspectiva, o AVA também pode contribuir com a expressão das subjetividades dos alunos que, durante as aulas de ciências, podem se sentir mais à vontade para expor seus pensamentos, além de colaborar no processo de desenvolvimento da autonomia, ao incentivar a organização escolar por parte do aluno, no sentido de que ele consiga gerir prazos, programar a realização de atividades e dedicar um horário específico para estudar (Duso, 2009; Lopes et al., 2014).

Frente a essa análise, percebemos que vários recursos utilizados na EaD juntamente com o advento do AVA mudaram a forma de difusão das informações, fazendo com que paradigmas da educação fossem quebrados, transformando o processo de ensino e aprendizagem dito tradicional, com o professor explicando e o aluno somente ouvindo, em algo mais dinâmico e dialógico.

No entanto, apesar de haver a preocupação por parte dos autores de que os processos educativos em ciências utilizem diferentes tipos de ferramentas como sinalizado por T2, nossa investigação mostra que as únicas ferramentas multimídias de fato utilizadas para a efetivação das pesquisas aqui analisadas foram o fórum e o chat.

Encontramos apenas um trabalho sobre o chat e que buscou avaliar como ocorre a evolução do perfil conceitual de um indivíduo dentro de um ambiente virtual em um curso de Astronomia. Nele, os tutores deveriam mediar as discussões:

O chat online tem potencial para provocar uma evolução do perfil conceitual do tema [...] Suas concepções apareceram e o perfil de cada aluno sobre a questão conceitual proposta ficou evidente, o que possibilitou ao tutor conduzir a discussão e trabalhar os elementos conceituais envolvidos (T4).

Percebe-se no excerto que o chat foi evidenciado de maneira positiva, tendo em vista que possibilitou ao tutor conduzir a discussão e trabalhar os elementos conceituais envolvidos, provocando uma evolução das representações que os alunos possuem sobre a ciência e sobre o cotidiano em que estão imersos.

Para Feitosa et al. (2013), o chat representa um recurso de comunicação que ocorre em tempo real, que pode aproximar os alunos entre si propiciando discussões semelhantes às que acontecem em uma sala de aula presencial. Isso aumenta a sensação de interação, pois representa uma forma de diálogo síncrono. Os mesmos autores 
defendem que as mensagens realizadas por meio dessa ferramenta permitem a interação dos discentes que têm mais liberdade para expor as ideias e que possibilita a cooperação para a construção do conhecimento, contribuindo para uma aprendizagem colaborativa.

Todavia, Oesterreich e Montoli (2010) discutem que o mesmo fator que faz o chat ser interessante, ou seja, sua comunicação em tempo real e síncrona, apresentam também alguns problemas, principalmente com a necessidade de todos possuírem a mesma disponibilidade de horário para o funcionamento, fator que se torna um empecilho levando em conta o cotidiano dos envolvidos. Além disso, os autores também discutem que os diálogos ocorridos por meio dessa ferramenta por serem realizados de maneira instantânea, podem não propiciar um tempo para amadurecimento do tema, gerando discussões superficiais e, portanto, sem bons resultados.

Outra ferramenta citada nos trabalhos que selecionamos foi o fórum. Em T1, o foco da investigação foi um fórum sobre ambiente marinho em um curso de Especialização para docentes em Biologia da Rede São Paulo, que buscou explorar múltiplos objetivos como: detectar os principais temas abordados pelos cursistas em suas postagens, avaliar a qualidade dos comentários e verificar se e como ocorreu a participação dos mediadores. Já em T5 buscou-se analisar as competências científicas expressas por alunos do curso de Licenciatura em Ciências no uso de ambientes assíncronos de comunicação numa disciplina que envolve a intervenção humana sobre o meio ambiente e suas consequências.

O primeiro trabalho evidencia a importância do fórum na aprendizagem, fazendo uma ressalva sobre a necessidade de formação de tutores para utilização dessa ferramenta, ressaltando pontos que podem ser melhorados para aumentar a familiaridade deles com o fórum:

Acreditamos que a participação efetiva dos mediadores num fórum é imprescindível para que esse instrumento tenha seus objetivos alcançados. Sendo assim, é necessário promover uma capacitação dos tutores para que eles possam, além de conhecer e aprender a utilizar as diversas ferramentas presentes nos ambientes virtuais de aprendizagem, compreender suas relevantes funções em todo o processo de ensino-aprendizagem na EAD. [...] Sugerimos ainda que o fórum apresente um enunciado mais claro e que enfoque uma questão que desencadeie uma discussão propriamente dita, por exemplo: "Quais as consequências e como minimizar o impacto humano em costões rochosos de áreas muito povoadas?". (T1).

Stelzer et al. (2014), em trabalho desenvolvido com o fórum, também defendem que para as potencialidades dessa ferramenta serem melhor aproveitadas, seria necessário que os tutores e professores passassem por capacitações, tendo em vista que a eficácia da ferramenta está diretamente relacionada com o seu planejamento e a sua articulação do conteúdo de modo que quem coordena o fórum possa direcionar as discussões e, consequentemente, permitir uma aprendizagem mais efetiva e/ou construção de competências por parte dos alunos. Esse fator também foi destacado em T5 quando há 
a afirmação de que: "[...] o fórum possibilitou a interatividade entre os participantes representando de certa forma, a sala de aula, viabilizando a interatividade entre aluno e professor para a construção de competências científicas" (T5).

Percebe-se que, ao tratar da construção de relações entre os participantes como um dos papéis dos fóruns, T5 utiliza o conceito de interatividade possível no contexto virtual que se constitui necessariamente por intermediações científico-tecnológicas, ao invés de se utilizar do conceito de interação, dado seu significado mais amplo que é peculiar as relações humanas cotidianas. Nesse trabalho percebemos também que os autores consideram possível a construção de competências científicas pelos alunos na relação com seus professores em ambientes virtuais como fóruns, pressuposto que pode contribuir para um alargamento e transgressão das fronteiras de aprendizagem e construção da ciência para outros espaços educativos que não apenas os hegemonicamente reconhecidos.

Nessa interlocução entre o ensino de ciências e os ambientes de aprendizagem, é importante pensar nos processos formativos que envolvem a construção de conhecimentos em ambientes de interatividade e dinamicidade. Esses fatores têm um potencial para reconstruir práticas no ensino de ciências que tenham como prioridade $o$ desenvolvimento de processos autônomos e integrados capazes de conciliar momentos virtuais e presenciais. Nesse sentido, Ferrari et al. (2009) apontam para a flexibilidade e liberdade que caracterizam os processos educativos advindos da EaD, especificamente com a utilização do AVA. Essa flexibilidade reside no fato de que a prática de ensino cria formas diferenciadas de imersão no processo de ensino que implicam em singularizados processos de interação, disponibilidade de estudo, desenvolvimento de atividades e avaliação.

Feitosa et al. (2013) contribuem para essa discussão esclarecendo que a característica do fórum é o debate e, consequentemente, a interatividade, uma vez que um tema é gerado e os participantes contribuem com a reflexão sobre o mesmo. Muitas vezes, além de aprofundar as ideias a respeito do assunto em questão, essas reflexões acabam por introduzir novos assuntos e conceitos que poderão gerar outros fóruns de debate.

Stelzer et al. (2014) atestam que as discussões geradas em fóruns se apresentam com uma riqueza tão grande de opiniões e experiências que os resultados dessa interatividade costumam ser superiores à ideia que originou o fórum. Isso ocorre porque essa ferramenta exige tanto a participação dos envolvidos quanto a integração e discussão de suas ideias com as dos outros participantes, o que favorece a construção do pensamento reflexivo e de competências sobre a ciência, conforme foi destacado em T5.

Apesar de essas duas ferramentas estarem devidamente explicadas nos trabalhos, no que diz respeito às suas potencialidades e desafios, percebemos que a diversificação de ferramentas é incipiente no conjunto das pesquisas aqui analisadas. Tenório et al. (2015) descrevem em seu trabalho outras ferramentas do AVA que existem para serem exploradas como o correio de mensagens, wiks e videoconferência. 
Albuquerque e Silva (2015) apontam para essa mesma realidade, pois acreditam que as disciplinas utilizam no decorrer das atividades as mesmas ferramentas tecnológicas, predominantemente os fóruns e chats, deixando de explorar uma variedade de outras ferramentas que, por sua especificidade, poderiam colaborar com o desenvolvimento de outras habilidades e competências por parte dos alunos.

Em síntese, podemos entender que chats, fóruns eo AVA vêm sendo compreendidos e utilizados como dimensões científico-tecnológicas que intermedeiam a relação entre os principais participantes do processo de ensino e aprendizagem em Ciências que ocorre em meio virtual. A Figura 3 apresenta as principais ferramentas multimídias e ambientes virtuais de aprendizagem utilizados pelos autores aqui analisados em suas pesquisas no que tange à sua utilização e os papéis que desempenham no processo de ensino e aprendizagem em Ciências.

Figura 3. Os usos e papéis das ferramentas multimídias e dos ambientes virtuais de aprendizagem empesquisas da área de Educação em Ciências no período de 2007 a 2019

\begin{tabular}{|c|c|c|}
\hline $\begin{array}{c}\text { Ferramentas e } \\
\text { ambientes virtuais mais } \\
\text { uti lizados }\end{array}$ & Papel que desempenham e/ou viabilizam & Trabalho \\
\hline AVA & $\begin{array}{l}\text { - Viabilização da interação; } \\
\text { - } \quad \text { Desenvolvimento de competências e habilidades; } \\
\text { - Promoção da motivação; } \\
\text { - Efetivação da comunicação. }\end{array}$ & T3 \\
\hline AVA & $\begin{array}{l}\text { - Resolução de problemas; } \\
\text { - Diálogo entre saberes científicos, cotidianos e } \\
\text { pessoais; } \\
\text { - Desenvolvimento da Criticidade. }\end{array}$ & T6 \\
\hline Chat e Fórum & $\begin{array}{l}\text { Promoção de um processo de ensino e aprendizagem } \\
\text { significativo. }\end{array}$ & $\mathrm{T} 2$ \\
\hline Chat & $\begin{array}{l}\text { - Construção de conceitos sobre a ciência em relação } \\
\text { com o cotidiano. }\end{array}$ & $\mathrm{T} 4$ \\
\hline Fórum & - Construção de competências científicas. & T5 \\
\hline Fórum & - Oportuniza a participação e a interação. & $\mathrm{T} 1$ \\
\hline
\end{tabular}

Percebe-se na Figura 3 que a aprendizagem sobre conceitos científicos é uma das contribuições em comum que tanto o AVA quanto fóruns e chats tornam possível em diferentes trabalhos e que está ligada ao desenvolvimento de uma postura científica, além do destaque para a motivação e interação entre os participantes e a relação entre diferentes saberes intermediados por essas ferramentas e ambientes virtuais. Essas finalidades, papéis e usos que assumem essas ferramentas e ambientes virtuais no contexto do ensino de ciências são complementares e podem colaborar para a ressignificação dos processos educativos sempre afinados com as necessidades e demandas contemporâneas. 


\section{Considerações finais}

Neste artigo procuramos analisar e caracterizar a produção científica sobre ferramentas multimídias e ambientes virtuais nos trabalhos apresentados no ENPEC quanto aos seus usos e papéis no processo de ensino e aprendizagem em Ciências. Percebemos que existem poucos trabalhos que priorizem a EaD como eixo principal e central de investigação. A inserção dessa modalidade de educação em pesquisas publicadas no ENPEC ainda é tímida, fato que reforça a necessidade de desenvolvimento de mais investigações nessa área.

Percebemos também que o fórum e o chat são as ferramentas tecnológicas mais utilizadas nas pesquisas, não havendo a diversificação de recursos digitais que poderiam contribuir para tornar o ensino de ciências a distância algo muito mais prazeroso, dinâmico e motivador.

Nesse sentido, sobre os usos que são feitos dessas ferramentas, nossa pesquisa evidenciou que as mesmas atuam no processo de intermediação científico-tecnológica favorecendo o desenvolvimento de papéis ligados a interação, motivação e relação de diferentes saberes que estão relacionados à aprendizagem de conceitos, a comunicação e a incorporação de elementos próprios da cultura científica. O AVA pode contribuir no processo de interação entre os diferentes atores da $\mathrm{EaD}$ e no desenvolvimento da aprendizagem, ao funcionar como um espaço que simula a sala de aula e uma base para que as diferentes ferramentas possam ser utilizadas.

Sobre o fórum, as pesquisas mostram que essa ferramenta é fundamental para a realização de discussões sobre determinado tema que podem contribuir para o desenvolvimento de competências científicas, além de viabilizar a interação e a participação no ambiente virtual. As discussões sobre o fórum são identificadas como ricas porque permitem que o aluno aprenda não somente externando seu ponto de vista, mas também considerando as ideias de seus colegas. Um aspecto desafiador dessa ferramenta no ensino de ciências está na necessidade de atentar para um planejamento didático-pedagógico bem feito por parte de tutores e professores, que por sua vez, carecem de formação adequada. Se os professores não forem devidamente formados para utilizar o fórum, a aprendizagem pode não ocorrer de maneira efetiva, além de haver possibilidade de perda de foco por parte dos participantes.

$\mathrm{O}$ chat tem como característica principal sua sincronicidade, ou seja, permitir que os alunos interajam em tempo real, ainda que em espaços diferentes. Uma potencialidade disso é que, dependendo da forma como o processo acontece, o chat pode revelar algumas características sócio cognitivas dos alunos e como eles reagem de maneiras espontâneas a determinado assunto e/ou conteúdo. No entanto, essa mesma vantagem pode se tornar um desafio uma vez que é comum nos chats que o assunto se perca ou que perca sua formalidade. Além disso, por ser síncrono, demanda que todos os envolvidos estejam presentes ao mesmo tempo na realização da atividade, algo que nem sempre é possível quando se trata do público que cursa uma $\mathrm{EaD}$. 
O chat tem como característica principal sua sincronicidade, ou seja, permitir que os alunos interajam em tempo real, ainda que em espaços diferentes. Uma potencialidade disso é que, dependendo da forma como o processo acontece, o chat pode revelar algumas características sócio cognitivas dos alunos e como eles reagem de maneiras espontâneas a determinado assunto e/ou conteúdo. No entanto, essa mesma vantagem pode se tornar um desafio uma vez que é comum nos chats que o assunto se perca ou que perca sua formalidade. Além disso, por ser síncrono, demanda que todos os envolvidos estejam presentes ao mesmo tempo na realização da atividade, algo que nem sempre é possível quando se trata do público que cursa uma EaD.

Os resultados encontrados nos fazem ressaltar a necessidade de que as especificidades da $\mathrm{EaD}$ sejam mais bem conhecidas e ganhem mais espaços na agenda de pesquisa da área de Educação em Ciências. Para tanto, sugerimos que essa modalidade possa ser estudada no âmbito das suas peculiaridades, em que as construções, experiências, percepções, recursos e estratégias encontradas dentro desse contexto possam nortear os desdobramentos necessários para ampliar ainda mais a oferta de cursos na modalidade da $\mathrm{EaD}$ que explorem de maneira adequada os abundantes e diversos caminhos teórico-metodológicos disponíveis para ela. Nesse sentido, é preciso que haja uma mobilização de toda a comunidade acadêmica que seja capaz de fortalecer a troca e compartilhamento de experiências, além de permitir discussões aprofundadas tanto sobre o próprio conhecimento dessa modalidade de ensino quanto sobre as ferramentas tecnológicas e ambientes virtuais que viabilizam a aprendizagem na $\mathrm{EaD}$.

$\mathrm{O}$ ensino de ciências na modalidade EaD implica uma ressignificação do conjunto de teorias e práticas sob as quais se assentaram as metodologias habitualmente utilizadas no contexto da sala de aula presencial, sobretudo quando consideramos as ferramentas multimídias e os ambientes virtuais de aprendizagem como tecnologias digitais que demandam um repensar das estratégias didático-pedagógicas utilizadas pelos tutores e professores. Evidentemente que essas tecnologias distanciadas de processos formativos críticos que possibilitem a reflexão, participação, engajamento e tomada de decisão por parte dos envolvidos, pouco podem contribuir para a necessária mudança paradigmática no campo educacional que incida na superação de concepções pedagógicas autoritárias e na direção de práticas educativas verdadeiramente dialógicas e, portanto, humanizadoras. Ampliar a compreensão que temos das potencialidades que envolvem a utilização dos ambientes virtuais e das ferramentas multimídias, bem como dos papéis que podem desempenhar no ensino de ciências significa multiplicar as possibilidades de fazer com que o processo de ensino e aprendizagem em ciências possa ocorrer de maneira a considerar de forma coerente as particularidades de acesso dos estudantes à ciência e tecnologia, bem como o proveito que eles podem tirar dessas dimensões no contexto da EaD.

É importante destacar que essas discussões tendem a ganhar ainda mais notoriedade e reconhecimento no contexto da pesquisa em educação e, particularmente, em Educação em Ciências, principalmente devido ao estado atual de emergência sanitária 
causada pelo SARS-CoV-2, que impõe a todos novas formas de ser e estar no mundo que não podem estar restritas aos momentos presenciais, mas que precisam considerar as alternativas virtuais. Não há dúvidas de que o estudo e investigação de novas ferramentas científico-tecnológicas adquirem uma importância significativa também nesse cenário, em que se almeja pensar estratégias que viabilizem a manutenção e ressignificação do ensino remoto e que potencializem seu alcance na direção do necessário enfrentamento de todas as formas de exclusão social.

Diante do exposto, entendemos que para a superação dos desafios presentes na contemporaneidade, mudanças nas agendas de pesquisa sobre a $\mathrm{EaD}$ são necessárias nas distintas áreas do conhecimento, incluindo a Educação em Ciências, com o intuito de encaminhamento dos problemas vivenciados e daqueles que porventura ainda vão surgir e que demandam um profundo conhecimento sobre o que significa viver em um mundo marcado pela ciência e pela tecnologia.

\section{Agradecimentos}

Agradecemos a Fundação de Amparo à Pesquisa do Estado da Bahia (FAPESB) pela bolsa de mestrado concedida.

\section{Referências}

Abreu-Tardelli, L. S. (2006). Aportes para compreender o trabalho do professor iniciante em EAD (Tese de Doutorado, Universidade Católica de São Paulo, São Paulo, São Paulo). Repositório PUCSP. https://tede2.pucsp.br/handle/handle/13799

Albuquerque, S. C., \& Silva, P. S. A. (2015). Estudo das tecnologias aplicadas à educação a distância. EntreVer-Revista das Licenciaturas, 4(6), 30-48. http://stat.ijie.incubadora. ufsc.br/index.php/EntreVer/article/view/3509/4187

Bacich L., \& Moran. J. (2018). Metodologias ativas para uma educação inovadora. Penso. Barbosa, P. P., Towata, N., Lima, T. F., Macedo, M., Saito, L. C., Delitti, W., \& Ursi, S. (05-09 de dezembro, 2011). Papel do fórum na Educação a Distância: Estudo de caso enfocando uma discussão sobre ambiente marinho na Rede São Paulo de Formação Docente. VIII Encontro Nacional de Pesquisa em Educação em Ciências (ENPEC), Campinas, São Paulo.

Carneiro, D., \& Silva, V. R. (15-26 de setembro, 2014). Educação à distância: Possibilidades e desafios. II Simpósio Internacional de Educação a Distância e II Encontro de Pesquisadores em Educação a Distância (SIED:EnPED), São Carlos, São Paulo.

Costa, K. S., \& Faria, G. G. (14-17 de setembro, 2008). EAD sua origem histórica, evolução e atualidade brasileira face ao paradigma da educação presencial. $14^{\circ}$ Congresso Internacional ABED de de Educação a Distância (CIAED), Santos, São Paulo.

Delizoicov, D., Angotti, J. A. P., \& Pernambuco, M. M. C. A. (2018). Ensino de Ciências: Fundamentos e métodos. Cortez. 
Duso, L. (2009). Uso de Ambiente Virtual de Aprendizagem de Temas Transversais no Ensino de Ciências. Revista Brasileira de Ensino de Ciência e Tecnologia, 2(3), 60-76. https://doi.org/10.3895/s1982-873×2009000300005

Feitosa, J. A. F., Lima, I. P., \& Vasconcelos, F. H. L. (2013). A ferramenta chat como recurso pedagógico no ensino de física. EaD em foco, 3(1), 1-14. https://doi.org/10.18264/eadf. v3i1.144

Ferrari, P. C., Angotti, J. A. P., \& Tragtenberg, M. H. R. (2009). Educação problematizadora a distância para a inserção de temas contemporâneos na formação docente: Uma introdução à Teoria do Caos. Ciência \& Educação, 15(1), 85-104. https://doi.org/10.1590/ s1516-73132009000100005

Filgueira, S. S., \& Santos, R. S. (03-06 de julho, 2017). Ambientes virtuais como configurações de aprendizagem: Análise de episódios interativo-discursivos em um curso técnico à distância. XI Encontro Nacional de Pesquisa em Educação em Ciências (ENPEC), Florianópolis, Santa Catarina.

Garcia, P. S., \& Gouw, A. M. S. (08-13 de novembro, 2009). Educação superior a distância: políticas, tendências da formação de professores de ciências. VII Encontro Nacional de Pesquisa em Educação em Ciências (ENPEC), Florianópolis, Santa Catarina.

Gil, A. C. (2006). Métodos e técnicas de pesquisa social. Atlas.

Hamawaki, M. H., \& Pelegrini, C. de M. A. (2009). Ferramentas do ensino a distância e suas contribuições para a eficácia no processo de aprendizagem do aluno. Revista CEPPG, (21), 84-91. http://www.portalcatalao.com/painel_clientes/cesuc/painel/ arquivos/upload/temp/b7632647fce4a8a50fda143156336f90.pdf

Junior, J. D., \& Scarinci, A. L. (24-27 de novembro, 2015). A evolução do perfil conceitual em um chat online de um curso à distância de Astronomia. X Encontro Nacional de Pesquisa em Educação em Ciências (ENPEC), Águas de Lindóia, São Paulo.

Lengler, F. R. (2014). Competências docentes na educação a distância: Estudo de caso no curso de tecnologia em processos gerenciais (Dissertação de Mestrado, Universidade Federal de Santa Catarina, Florianópolis, Santa Catarina). Repositório Institucional UFSC. https://repositorio.ufsc.br/handle/123456789/130940

Lima, D. da. C. B. P. (2014). Projeto CNE/UNESCO 914BRZ1142.3: Desenvolvimento, aprimoramentoeconsolidaçãodeumaeducaçãonacionaldequalidade -educaçãoadistância na educação superior. Ministério da Educação/Conselho Nacional de Edcuação. http:// portal.mec.gov.br/index.php?option $=$ com_docman\&view=download\&alias=16511produto-02-estudo-processo\&Itemid $=30192$

Lopes, P. T. C., Almeida, C. M. M., \& Costa, R. D. A. (2014). Ensino de Ciências através de Tecnologias de Informação e Comunicação: Utilizando uma sequência didática eletrônica e um ambiente virtual de aprendizagem. Acta Scientiae, 6(4), 161-177. http:// www.periodicos.ulbra.br/index.php/acta/article/view/1273/1025 
Maganha, L. F., Souza, L. W., Versuti Stoque, F. M., \& Prette, N. (24-27 de novembro, 2015). Análise da atividade assíncronas: Fóruns de discussões em um curso de Licenciatura em Ciências Semipresencial. X Encontro Nacional de Pesquisa em Educação em Ciências (ENPEC), Águas de Lindóia, São Paulo.

Maia, M. C. (2003). O uso da tecnologia de informação para a Educação a Distância no Ensino Superior (Tese de Doutorado, Escola de Administração de Empresas de São Paulo da Fundação Getúlio Vargas, São Paulo, São Paulo). FGV Repositório Digital. http://bibliotecadigital.fgv.br/dspace;/bitstream/handle/10438/2463/74603.pdf

Marconi, M. de A., \& Lakatos, E. M. (2003). Fundamentos de metodologia científica. Atlas.

Martinho, T., \& Pombo, L. (2009). Potencialidades das TIC no ensino das Ciências Naturais: Um estudo de caso. Revista Electrónica Enseñanza de las Ciencias 8(2), $527-$ 538.

Martins, C. A. (2011). Práticas educativas digitais: Uma história, uma perspectiva (Dissertação de Mestrado, Universidade Federal do Ceará, Fortaleza, Ceará). Repositório Institucional UFC. http://www.repositorio.ufc.br/handle/riufc/13221

Mayer, M., Bastos, H., Costa, S., \& Numeriano, J. (2001). Ensino de ciências em ambientes virtuais: A percepção do professor sobre as diferenças na sua prática introduzidas pelo uso das novas tecnologias. Revista Brasileira de Pesquisa em Educação em Ciências, 1(1), 132-139. https://periodicos.ufmg.br/index.php/rbpec/article/view/4190

Ministério da Educação (2007). Referenciais para elaboração de material didático para EaD no Ensino Profissional e Tecnológico. https://docplayer.com.br/37493910Referenciais-para-elaboracao-de-material-didatico-para-ead-no-ensino-profissional-etecnologico.html

Mendes, A. (2008). TIC - Muita gente está comentando, mas você sabe o que é? Portal iMaster. https://imasters.com.br/devsecops/tic-muita-gente-esta-comentando-masvoce-sabe-o-que-e

Minus, L. E. L., \& Sorte, L. X. B. (10-22 de setembro, 2012). O uso de ferramentas multimídias e de novas tecnologias no processo de ensino e aprendizagem na educação a distância. I Simpósio Internacional de Educação a Distância e I Encontro de Pesquisadores em Educação a Distância (SIED:EnPED), São Carlos, São Paulo.

Moraes, R. (1999). Análise de conteúdo. Revista Educação, 22(37), 7-32. https:// edisciplinas.usp.br/pluginfile.php/4125089/mod_resource/content/1/Roque-Moraes_ Analise\%20de\%20conteudo-1999.pdf

Moran, J. M. (2006). Avaliação do ensino superior a distância no Brasil. http://www2.eca. usp.br/moran/wp-content/uploads/2013/12/avaliacao.pdf 
Morgado, L. (2001). O papel do professor em contextos de ensino online: Problemas e virtualidades. Discursos, III(spe), 125-138. https://repositorioaberto.uab.pt/ bitstream/10400.2/1743/1/professor_online_linamorgado.pdf

Nardi, R., \& Almeida, M. J. P. M. (2007). Investigação em ensino de ciências no Brasil segundo pesquisadores da área: Alguns fatores que lhe deram origem. Pro-Posições, 18(1), 213-226. https://periodicos.sbu.unicamp.br/ojs/index.php/proposic/article/ view/8643587

Nobre, I. A., Nunes, V. B., Baldo, Y. P., Moura, E. S., \& Carneiro, D. V. (27-30 de setembro, 2009). Curso Superior de Análise e Desenvolvimento de Sistemas: Relato de uma experiência pioneira de EAD no Ifes na percepção do aluno Serra. $15^{\circ}$ Congresso Internacional ABED de Educação a Distância (CIAED), Fortaleza, Ceará.

Novais, J. S. (2009). Metodologia da pesquisa e do ensino de Ciências e Biologia em cursos a distância: Questões teóricas. Revista Brasileira de Aprendizagem Aberta e a Distância, 8(0), 1-20. https://doi.org/10.17143/rbaad.v8i0.221

Oesterreich, F., \& Montoli, F. S. (2010). Potencialidades e fragilidades das ferramentas tecnológicas em ambientes virtuais de aprendizagem. Revista Tecnologias na Educação, 3(2), 1-10. http://tecedu.pro.br/wp-content/uploads/2015/07/Art2-ano2-vol3dezembro2010.pdf

Oliveira, C., Moura, S. P., \& Sousa. E. R. (2015). TIC’s na Educação: A utilização das tecnologias da informação e comunicação na aprendizagem do aluno. Pedagogia em Ação, 7(1), 75-95. http://periodicos.pucminas.br/index.php/pedagogiacao/article/ view/11019

Paula Filho, W. de P. (2000). Multimídia: Conceitos e Aplicações. LTC.

Paulo, W. de. O., \& Giordan. M. (10-13 de novembro, 2013). Construção de indicadores na dimensão rendimento para cursos de formação continuada de professores em ambientes virtuais de aprendizagem. IX Encontro Nacional de Pesquisa em Educação em Ciências (ENPEC), Águas de Lindóia, São Paulo.

Ribeiro, E. N., Mendonça, G. A. de A., \& Mendonça, A. F. (2007). A importância dos ambientes virtuais de aprendizagem na busca de novos domínios da EaD. $13^{\circ}$ Congresso Internacional de Educação a Distância (CIED). Curitiba, Paraná.

Rodrigues, J. E., \& Fernandes, F. J. (2014). Proposta de inclusão de carga horária semipresencial em cursos superiores presenciais. Avaliação, 19(1), 179-192. https://doi. org/10.1590/s1414-40772014000100009

Sales, R. G., \& Mello, I. C. (2017). Os ambientes virtuais de aprendizagem: Contribuições para o ensino de ciências. FLOVET - Boletim do Grupo de Pesquisa da Flora, Vegetação e Etnobotânica, 1(9), 17-30. https://periodicoscientificos.ufmt.br/ojs/index.php/flovet/ article/view/5484 
Sanchez, F. (Coord.) (2005). Anuário Brasileiro de Educação Aberta e a Distância. Instituto Cultural/Editora Monitor.

Scarinci, A. L. (05-09 de dezembro, 2013). A comunicação pedagógica em um curso à distância. VIII Encontro Nacional de Pesquisa em Educação em Ciências (ENPEC) e I Congreso Iberoamericano de Investigación en Enseñanza de las Ciéncias (CIEC), Campinas, São Paulo.

Silva, A. C. R. (07-10 de setembro, 2004). Educação a distância e o seu grande desafio: $O$ aluno como sujeito de sua própria aprendizagem. $11^{\circ}$ Congresso Internacional de Educação a Distância (CIED), Salvador, Bahia.

Silva, C. A., Veras, I. R., Reis. L., \& Santos. M. A. (06-09 de outubro, 2014). Educação a distância: A visão de professores e alunos acerca dessa modalidade de ensino. $20^{\circ}$ Congresso Internacional ABED de Educação a Distância (CIAED), Curitiba, Paraná.

Silva, M. P. D., Melo, M. C. D. O. L., \& Muylder, C. F. D. (2015). Educação a distância em foco: Um estudo sobre a produção científica brasileira. Revista de Administração Mackenzie, 16(4), 202-230. https://doi.org/10.1590/1678-69712015/administracao. v16n4p202-230

Segenreich, S. C. D. (2009). ProUni e UAB como estratégias de EAD na expansão do ensino superior. Pro-Posições, 20(2), 205-222. https://doi.org/10.1590/s010373072009000200013

Stelzer, J., Gonçalves, E. N., Junior, G. R., Alves, M. A. S., \& Alves, J. A. S. (03-05 de dezembro, 2014). Fórum EaD e o (des) conhecimento da ferramenta pelos atores do processo de ensino e aprendizagem. XIV Colóquio Internacional de Gestão Universitária (CIGU), Florianópolis, Santa Catarina.

Teixeira, R. C., Piotto, K. D. B., \& Bonzanini, T. K. (24-27 de novembro, 2015). Ensinar e aprender em um curso de Licenciatura em Ciências na modalidade semipresencial: Questões para a prática e formação docente. X Encontro Nacional de Pesquisa em Educação em Ciências (ENPEC), Águas de Lindóia, São Paulo.

Tenório, T., Laudelino, M. A., \& Tenório, A. (2015). A Importância do Ambiente Virtual de Aprendizagem em um curso de graduação com base nas percepções de alunos a Distância. EaD em foco, 5(3), 11-36. https://doi.org/10.18264/eadf.v5i3.274 
${ }^{[0}$ Rutiléa Mendes de Morais

Universidade Estadual do Sudoeste da Bahia Vitória da Conquista, Bahia, Brasil rutidiscipula@gmail.com

Rodrigo da Luz

Universidade Federal da Bahia Salvador, Bahia, Brasil rodrigoluz_saj@live.com

Benedito Gonçalves Eugênio

Universidade Estadual do Sudoeste da Bahia Vitória da Conquista, Bahia, Brasil benedito.eugenio@uesb.edu.br

Editor Responsável

Alessandro Gomes

Manifestação de Atenção às Boas Práticas Científicas e de Isenção de Interesse

Os autores declaram ter cuidado de aspectos éticos ao longo do desenvolvimento da pesquisa e não ter qualquer interesse concorrente ou relações pessoais que possam ter influenciado o trabalho relatado no texto. 